\title{
POSSÍVEIS CONTRIBUIÇÕES DO PROFESSOR DE EDUCAÇÃO FÍSICA NA DESCOBERTA E PREVENÇÃO DE CASOS DE VIOLÊNCIA SEXUAL
}

\section{Possible contributions of the professor of physical education in the discovery and prevention of cases of sexual violence}

\begin{abstract}
Jessica Luiza de Oliveira Nascimento - Universidade Estadual do Norte do Paraná/Brasil Miriam Cristina Cavenaghi Sibila - Universidade Estadual do Norte do Paraná/Brasil Débora Alves Guariglia - Universidade Estadual do Norte do Paraná/Brasil
\end{abstract}

\begin{abstract}
RESUMO: Milhões de crianças e adolescentes são marcados com a perpétua dor da violência sexual, ainda que seja a violência menos denunciada no Brasil. Este tipo de violência traz sérios danos à formação do indivíduo, que precisa imediatamente de auxílio para que haja minimização do trauma. Situações como estas trazem a necessidade de elencar informações suficientes para a caracterização da violência e seus aspectos, suas formas de ocorrência e exposição, sendo assim, por intermédio desta revisão bibliográfica foi possível apontar possibilidades para que professores, sobretudo os de educação física, possam auxiliar na prevenção e identificação de crianças e adolescentes vítimas desta violência.
\end{abstract}

Palavras-chave: Abuso sexual. Crianças e adolescentes. Docente. Educação Física. Escola.

ABSTRACT: Millions of children and adolescents are marked with the perpetual pain of sexual violence, although it is the least reported violence in Brazil. This type of violence brings serious damage to the formation of the individual, who immediately needs help for the liquidation of the trauma. Situations such as these bring the need to provide sufficient information for the characterization of violence and its aspects, its forms of occurrence and exposure, thus, through this bibliographic review it was possible to point out possibilities teachers, especially those of physical education, can help in the prevention and discovery of children and adolescents who are victims of this violence.

Keywords: Children and adolescents. Physical Education. School. Sexual abuse. Teacher.

\section{INTRODUÇÃO}

A Escola é uma instituição composta pela equipe pedagógica, colaboradores e seus doscentes, os quais possuem o objetivo de cooperar na formação do indivíduo na sua integralidade, considerando os aspectos cognitivo, social e cultural, juntamente com o primeiro ambiente mais vivenciado: a família. A equipe pedagógica permanece próxima

Educação, Psicologia e Interfaces, Volume 4, Número 3, p. 1-14, Julho/Setembro, 2020.

ISSN: 2594-5343. DOI: 10.37444/issn-2594-5343.v4i3.267 
aos alunos e seu contato direto para com eles a torna capaz de observar possíveis situações problemáticas nos alunos, dentre elas, a violência sexual.

A violência sexual caracteriza-se como qualquer tipo de interação entre uma criança e um adolescente ou outro indivíduo, em estágio mais avançado de desenvolvimento, onde exista o uso do outro para algum tipo de estímulo sexual (HABIGZANG et al., 2005).

Em estudos realizados pelo Instituto de Pesquisa Econômica Aplicada (IPEA, 2014) e o Sistema de Informação de Agravos de Notificação (SINAN, 2017) revelou-se que os agressores, majoritariamente, estão ligados ao ambiente familiar, sendo eles pais (14\%), padrastos (28\%), irmãos (2\%), avôs (6\%) e parentes (10\%) (SILVA, 2020). O que pode dificultar a estruturação do desenvolvimento do indivíduo, colocando a escola como principal fonte de amparo e formação, visto que $94 \%$ das crianças vítimas de violência frequentam o ambiente escolar (SILVA, 2020).

O abuso sexual gera traumas que podem ser ampliados nos períodos de infância e adolescência, pois irão requer mudanças significativas destes indivíduos, para que se compense, ou minimize o trauma resultante de tal situação (HABIGZANG apud AMAZARRAY; KOLLER, 1998; COHEN; MANNARINO, 2000; HABIGZANG; CAMINHA, 2004; JONZON; LINDBLAD, 2004).

Faleiros e Faleiros (2008) conceituam que o desprezo, a falta de preparo e a negligência ao lidar com as vítimas é outro tipo de violência que elas podem sofrer durante a busca por assistência. Conhecida como violência institucional, pode se apresentar na forma física, psíquica e/ou sexual e está associada aos locais onde ocorre, como instituições de ensino, saúde, abrigos, entre outros, que pode levar a ocorrência de casos mais graves ou até mesmo a morte da vítima.

Como forma de combate e de prevenção contra a violência sexual, Meyer (2017) sugere que umas das ações mais eficazes, é falar sobre o problema. Assim torna-se imprescindível abordar a "sexualidade" e as formas de violência na escola, visto que o assunto aparece como tema transversal na Base Nacional Comum Curricular (2017). Além disto, conforme se postula no Estatuto da Criança e do Adolescente, é "dever da família, da comunidade, da sociedade em geral e do Poder Público assegurar, com absoluta prioridade, a efetivação dos direitos referente à vida" (ECA, 1990).

Educação, Psicologia e Interfaces, Volume 4, Número 3, p. 1-14, Julho/Setembro, 2020.

ISSN: 2594-5343. DOI: $10.37444 /$ issn-2594-5343.v4i3.267 
Possíveis contribuições do professor de educação física na descoberta e prevenção de casos de violência sexual

Em estudos dirigidos por Castro-Sandoval (2019), a exclusão do tema "sexualidade" resultou em um aumento significativo de casos de doenças sexualmente transmissíveis, juntamente com as denúncias de casos de violência sexual. Portanto, a exclusão da temática nas aulas não coopera para a redução da erotização da criança como popularmente se acredita, mas sim promove uma sexualidade sem conhecimento e consequentemente, sem a prevenção ou conscientização a respeito dos cuidados e riscos de abusos.

Ao abordar a sexualidade no ambiente escolar, em seus aspectos biológico, cultural, social e emocional, de forma adequada e responsável, cria-se uma rede de apoio aos estudantes, auxiliando-os a melhor compreensão do assunto e a sensação de apoio e amparo tão necessários a situação.

Nesse sentido, o objetivo do presente estudo foi levantar informações na literatura para auxiliar professores na identificação de vítimas de violência sexual, além de propor atividades sugestivas para prevenção e descoberta da mesma.

\section{MATERIAL E MÉTODO}

Este estudo caracteriza-se como revisão de literatura, pois apresentam uma busca incessante a respeito de informações sobre o tema que objetiva servir de base para futuros experimentos, assim como Souza e Diesel (2008) sugerem.

\subsection{Procedimentos}

Buscou-se de forma não sistemática todos os títulos, livros e cartilhas relacionados ao tema, disponíveis digitalmente em língua portuguesa do Brasil. Para isso, nas buscas foram utilizadas as palavras chaves: abuso sexual, violência sexual, estupro, escola, casos e escolar. Para integrarem este estudo, os artigos selecionados referenciam a violência sexual em crianças e adolescentes, o contexto das descobertas de violência sexual pelo docente e a prática do professor de educação física enquanto contribuinte na revelação de casos de violência sexual sofrida por alunos, dentro ou fora do contexto escolar.

\section{RESULTADOS E DISCUSSÃO}

\subsection{O que é "violência sexual"?}

Educação, Psicologia e Interfaces, Volume 4, Número 3, p. 1-14, Julho/Setembro, 2020. 
A violência sexual possui inúmeras vertentes e pode ser reconhecida também pelos termos "abuso sexual", "estupro" e "assédio sexual", uma vez que se referem a um grande número de atos violadores dos direitos humanos. Habigzang et al (p.341, 2005) sugere:

Esta forma de violência pode ser definida como qualquer contato ou interação entre uma criança ou adolescente e alguém em estágio psicossexual mais avançado do desenvolvimento, na qual a criança ou adolescente esteja sendo usado para estimulação sexual do perpetrador.

Sendo assim, o abuso sexual não requer necessariamente o toque por parte do agressor, pode ser capaz de não deixar vestígios e marcas evidentes da violência, o que acaba por dificultar a identificação nítida de vítimas.

Segundo a Associação Brasileira Multiprofissional de Proteção à Infância e à Adolescência (ABRAPIA, 2002), a violência de aspecto sexual pode ocorrer de diferentes maneiras, como o abuso sexual verbal, exibicionismo, voyeurismo, exibição de conteúdo sexual para crianças ou adolescentes, fotografar crianças nuas ou de aspecto sexual, atos físicos-genitais, pornografia e prostituição, estupro, atentado violento ao pudor, incesto e assédio sexual. Ou seja, qualquer comportamento de natureza sexual, seja ela verbal ou física, com ou sem contato físico que viole os direitos da criança e adolescente é considerado uma violência sexual.

$\mathrm{Na}$ forma verbal caracteriza-se pela indução das vítimas a conversas a respeito de atividades de cunho sexual, provocando choque ou interesse (precoce) dos mesmos, podendo ocorrer propostas ou até mesmo chantagens.

Em crianças e adolescentes, é uma forma de delito que tira de suas vítimas o direito de desenvolvimento de sua sexualidade (FALEIROS; FALEIROS, 2008). Quaisquer umas destas formas de violência podem agregar à criança ou adolescente diversas complicações imediatas ou ao decorrer de suas vidas.

\subsection{Consequências de um indivíduo traumatizado}

Fisiologicamente, em alguns estudos desenvolvidos por Teicher et al. (2002) notou-se que o hemisfério esquerdo do cérebro de pacientes vítimas de abuso desenvolveu-se menos que o grupo de pacientes sem trauma. O hemisfério esquerdo é responsável pela percepção e linguagem. A diferença do trabalho entre os hemisférios 
Possíveis contribuições do professor de educação física na descoberta e prevenção de casos de violência sexual

predispõe o deslocamento de funções, fazendo com que o cérebro utilize o hemisfério direito, trazendo percepções e memórias emocionais diferentes e extremas. O trauma é capaz de provocar uma irritabilidade elétrica no sistema límbico ${ }^{1}$ que produz sintomas de agressão e ansiedade.

Os sintomas mais frequentes obtidos por estudos de Silva (2020) em crianças vítimas de violência sexual foram: dor abdominal (17\%), falta de apetite (13\%), náuseas, vômitos e enjoos (10\%), dor no peito (9\%), enurese (6\%), dor na genitália (6\%), dor de cabeça (4\%), encoprese (3\%), infecção urinária (1\%), desmaio (1\%), 32\% não souberam informar ou não apresentaram sintomas.

Para Oliveira e Sei (2014) um trauma pode ser classificado como qualquer tipo de estímulo que a psique seja incapaz de metabolizar. Freud (1980) sugere que a incidência de violência sexual ocasiona traumas psíquicos que afetam negativamente a organização psíquica e acarretam feridas que atacam precocemente o ego ${ }^{2}$. Este teórico ressalta ainda que o trauma pode instalar-se de tal forma no aparelho psíquico de uma pessoa, que se torna um passado constantemente presente na vida da pessoa.

Abraham e Torok (1978) citam algumas perturbações e reforços de mecanismos de defesa como "a negação, a cisão, a identificação projetiva, a idealização, a onipotência, entre outros que podem organizar zonas psíquicas mortas, criptas”. O ego, cuja finalidade é de equilibrar as emoções entre o Id (princípio do prazer) e o Superego (moral e censura) pode ser tão prejudicado a ponto de provocar distorções de sua autonomia, quando o agressor está dentro do círculo familiar da vítima, já que existe a quebra da confiança com adultos próximos e sentimento de insegurança, favorece a desconfiança em pessoas em geral, ocasionando futuros problemas de relacionamento. Tal fato resulta em indivíduos com insegurança, falta de autoconfiança e baixa autoestima, transtornos esses que podem levar "uma vida" para serem superados.

\footnotetext{
1 O sistema límbico é a unidade responsável pelas emoções e comportamentos sociais. É uma região constituída de neurônios, células que formam uma massa cinzenta.

2 Ego (em alemão ich, "eu") é o chamado princípio da realidade. É esse princípio que introduz a razão, o planejamento e a espera no comportamento humano.
}

Educação, Psicologia e Interfaces, Volume 4, Número 3, p. 1-14, Julho/Setembro, 2020.

ISSN: 2594-5343. DOI: 10.37444/issn-2594-5343.v4i3.267 
A desconfiança para com outras pessoas traz a criança e ao adolescente um afastamento das mesmas, que posteriormente poderá seguir rumos como a promiscuidade, na busca excessiva por afeto ou o isolamento e depressão (PRADO; CARNEIRO, 2005).

Uma vez que a criança ou adolescente não consiga estabelecer confiança para com outras pessoas, o diálogo sobre seus traumas pode não ocorrer com facilidade ou até mesmo nunca acontecer verbalmente, considerando a incapacidade da vítima de reagir perante a situação, algo característico do trauma. Para isto, a compreensão de diversas formas de linguagem torna-se de suma importância para que o docente seja capaz de captar pedidos de ajuda ou falar sobre o assunto.

\subsection{A escola como ambiente protetor}

A frágil efamiliar observada nos casos atendidos influencia diretamente no desenvolvimento da criança ou adolescente. Estes vêm sofrendo com a vulnerabilidade das uniões. (CEDCA/PR, 2003, p.07)

Nasce então, a urgência de que a escola se torne um ambiente acolhedor. Esta urgência torna-se ainda mais agravada ao constatar que a violência acontece principalmente em âmbito intrafamiliar e próximos a ele.

A falta de cuidados, de quem na verdade deveria auxiliar na proteção de crianças e adolescentes, como a escola, faz a vítima sofrer outras violências como a institucional. Faleiros e Faleiros (2008, p.38) completam:

Existe, em nível institucional, um outro tipo de violência que pode passar despercebida, que é a negligência profissional. Sua manifestação caracteriza-se pelo desprezo (por desinteresse, despreparo ou incompetência) pelas outras formas de violência e de violação dos direitos de crianças e adolescentes, ignorando os sinais de risco e a existência de processos violentos em curso que poderão levar a violências mais graves (como a sexual, por exemplo) ou até mesmo a morte.

Um professor omisso, automaticamente, torna-se mais um violador dos direitos da criança e do adolescente. Não denunciar ou desconsiderar a existência de casos de abuso sexual corroboram para que os agressores não sejam identificados e punidos por suas ações, o que o torna mais um agressor ao não tentar minimizar os impactos causados pelo abuso sexual (PRADO; CARNEIRO, 2005). O professor que sustenta a idealização de que a escola é para os alunos e assim empenha-se a zelar por seu desenvolvimento, pode ser capaz de transformar a realidade de diversas crianças.

Educação, Psicologia e Interfaces, Volume 4, Número 3, p. 1-14, Julho/Setembro, 2020.

ISSN: 2594-5343. DOI: 10.37444/issn-2594-5343.v4i3.267 
Possíveis contribuições do professor de educação física na descoberta e prevenção de casos de violência sexual

\subsection{Educação física, linguagem corporal e a violência sexual}

Históricamente, com as transformações sofridas pela Educação Física, seu objetivo passou a ser a colaboração na formação de seres humanos integralmente, cabidos de seus corpos e da maneira com que se posicionam no mundo. $\mathrm{O}$ discurso atual desta disciplina salienta a necessidade de o professor abrir-se para novas realidades, tornando-se mais humano, para que seja capaz de transmitir saberes positivos na formação do indivíduo.

Então, quando a Educação Física lida com o conteúdo "basquetebol" ou "dança", o objetivo não deve ser apenas chegar às formas institucionalizadas/codificadas de movimentar-se nessas atividades, ou à conceitualização/teorização como ápice do processo de ensino e aprendizagem, porém, abrir espaço também para novas mensagens gestuais, imprevistas e inusitadas (GOMES-DA-SILVA; SANT`AGOSTINHO; BETTI, p.37, 2005).

A ação corporal citada por Vayer e Tolouse (1985) notoriamente carregada de sentimentos, impossibilitando desmembrar corpo e mente, está presente na disciplina de educação física, mas é necessário estar atento ao tipo de metodologia utilizada durante as aulas. Uma vez que uma abordagem exclusivamente tecnicista visa apenas a construção de habilidades motoras, incapazes de abrirem-se suficientemente para que a criança se expresse, ao mesmo tempo, um professor exclusivamente tecnicista tende a ensinar movimentos sem significados, apenas habilidades copiadas de corpos para corpos. Ainda assim, a educação física promove diversos eventos capazes de expor ações motoras, sendo ela, a disciplina que permite de forma ampla a descoberta de casos de violência sexual na escola, visto que recebe o maior número de informações em diferentes tipos de linguagens durante a vivência da vítima na escola.

A nova proposta da Educação Física escolar traz além da comunicação verbal, ofertando também a comunicação não verbal, que para Vayer e Tolouse (1985) é capaz de ocorrer por meio do comportamento, continuamente carregado de significados que podem ser captados caso alguém se disponha a interpretá-los, favorecendo a identificação de crianças e adolescentes em situação de risco.

Para Ehrenberg (2014), durante a execução dos movimentos corporais é que a criança expressa suas emoções de modo intencional, capaz de representar coberto de sentidos e significados. O que traz à tona que não apenas a oralidade é uma forma de linguagem, mas todos os elementos que compõe a cultura corporal.

Educação, Psicologia e Interfaces, Volume 4, Número 3, p. 1-14, Julho/Setembro, 2020.

ISSN: 2594-5343. DOI: 10.37444 /issn-2594-5343.v4i3.267 
O corpo fala: a postura, as atitudes, os gestos, os olhares são capazes de exprimir muito mais eficazmente as sensações e emoções de um indivíduo em determinado contexto, expressas por outro hemisfério de nosso cérebro de maneira não filtrada (VAYER; TOLOUSE, 1985). Ou seja, considerar a linguagem não expressa em meras palavras traz autenticidade à comunicação de emoções, já que comumente casos de violência sexual não são relatados por diversos fatores como medo, vergonha, culpa e ameaça dos agressores.

Brino e Williams (2003) demonstram que 65\% dos professores analisados possuíam verbalizações inadequadas para lidar com a situação, e pouco ou pouquíssimo conhecimento sobre o Estatuto da Criança e do Adolescente (ECA), sendo que apenas $21 \%$ das professoras faria a denúncia, como estabelece o Estatuto.

O corpo docente é um fator determinante para proteção e prevenção de vítimas desta violência, mas que se mostram despreparados para lidar com o tema, sendo assim extremamente necessário que sejam proporcionadas capacitações para que os professores adquiram embasamento e preparação para lidar com um assunto que, embora tão presente, ainda se configura como um tabu (LISBOA et al., 2002).

O distanciamento na relação aluno-professor não coopera para o desenvolvimento de elos de confiança para que a vítima se sinta confortável em conversar ou demonstrar seus anseios e angústias. É essencial observar o ser humano em sua totalidade, o que é parte do papel do educador, sendo necessário que durante as aulas o mesmo seja capaz de incentivar a expressividade das emoções de seus alunos e não os tornar a repetir movimentos.

\subsection{Propostas de atividades e reflexões na educação física escolar}

Baseado nos aspectos favoráveis para prevenção e descoberta de casos de violência sexual, algumas atividades aqui descritas podem suplementar as atividades curriculares, como:

1. Pega-rabo - esta brincadeira tem como objetivo pegar o maior número de "rabos" possíveis, para isto, são colocadas fitas junto as vestes inferiores de modo a assemelhar-se a uma cauda. Cada aluno deverá portar um rabo, protegendo-o e caçando novos. Esta brincadeira requer o toque de uns com os outros alunos, toque este que deve ser consentido. Antes de iniciar a brincadeira, deve ser feita uma 
Possíveis contribuições do professor de educação física na descoberta e prevenção de casos de violência sexual

roda de conversa, onde deverá perguntar aos alunos se sentem confortáveis com a localização do rabo, podendo alterar o local, ressaltando que os colegas só poderão tocar onde está delimitado pelo aluno. Durante a roda de conversa, é possível demonstrar o significado de consentimento e suas vertentes.

2. Estoura balão - divididos em duas fileiras, os alunos terão em mãos um papel e uma caneta, onde escreverão suas dúvidas a respeito de "sexualidade", chegando ao outro lado da quadra, receberão uma bexiga para colocar o papel dentro e enchê-la e posteriormente, amarrando em um barbante. As cores entre grupos devem diferenciar-se. A equipe que mais balões tiver, vence. Ao final, cada aluno estourará a bexiga do outro grupo para que possa ler as dúvidas que por fim, serão discutidas em roda de conversa.

Nesta atividade, visa-se o enfrentamento do tabu que este tema traz. Para isto, é necessário que o professor adote uma postura receptiva a questionamentos e diálogo, para que os alunos se sintam tranquilos a realizar perguntas. Mas a atividade também é capaz de abranger àqueles que não tem coragem de questionar, já que as dúvidas se misturam em meio aos balões. Esclarecer aspectos da sexualidade é uma forma de prevenção da violência sexual.

3. Jogo da garrafa - em forma de roda, sentados ao chão, o professor deve apresentar o tema "sexualidade", conduzindo a roda de conversa, que utilizará uma garrafa para apontar um aluno que poderá fazer uma pergunta sobre o tema ou falar algo que tenha conhecimento prévio e queira compartilhar com os colegas. Caso os alunos permaneçam intimidados, o professor poderá levar "tabus" sobre o tema para serem discutidos. Onde torna-se um momento importante e propício para que o professor fale sobre consentimento e assédio.

A roda de conversa é recurso muito importante para propagação de conhecimento, para isto o professor deve alinhar-se aos seus alunos, de modo a estar disposto a conversar e ouvir dúvidas. A aproximação de professor e aluno é essencial nesta fase.

4. Marcação - como no futebol, futsal, handebol, basquetebol, entre outros é inevitável que exista contato, principalmente durante as marcações de adversários. Durante a atividade, pode-se fazer uma breve apresentação dos fundamentos de qualquer um dos esportes de contato, dando ênfase a marcação. Durante a apresentação deste fundamento, é possível apresentar os locais permitidos para

Educação, Psicologia e Interfaces, Volume 4, Número 3, p. 1-14, Julho/Setembro, 2020. ISSN: 2594-5343. DOI: 10.37444 /issn-2594-5343.v4i3.267 
toque e aqueles que são irregulares, enfatizando o porque. Nesta atividade é possível abranger conceitos de consentimento e respeito ao corpo do outro, além da percepção de ações irregulares no cotidiano.

5. Lutas - em lutas de curta distância, ao apresentar seus fundamentos, fazer uma breve explicação dos locais apropriados para agarramento e ataque, exaltando a necessidade do respeito mútuo durante a luta, o respeito com o próprio corpo e corpo do colega afim de que não ocorram lesões e irregularidades. O ponto mais forte desta aula é a aquisição de respeito mútuo. Blanchard (1996, p.7) completa:

ter vivido um trauma físico e psicológico faz com que a vítima questione sua capacidade de defender-se... Ela aprende a odiar seu corpo porque ele a faz lembrar de más experiências. Ela tem respostas dissociadas, apresenta dificuldade de intimidade e é emocionalmente distante. Ela aprende que não pode controlar seu corpo e que outra pessoa pode tocála sem o seu consentimento. Ela não confia na sua memória, nos seus pensamentos e no seu senso de realidade. Essas consequências afetam não só a vítima, mas também a sociedade em geral porque uma criança traumatizada torna-se eventualmente um adulto que pode adotar comportamentos agressivos ou passivos para resolver as situações e o estresse.

6. Dança - inicialmente, o professor deve fazer uma breve apresentação ao conteúdo, enfatizando a importância do conhecimento do próprio corpo e o respeito mútuo. Em um segundo momento, o professor deverá ter em mãos em média cinco tipos de dança ou temas que serão distribuídos aos grupos formados por até seis alunos. Os alunos deverão cada um elaborar uma coreografia relacionada ao tema, utilizando de seu conhecimento corporal e respeito com o corpo do outro. O contato físico é obrigatório.

Neste momento da aula, é possível observar a forma com que os alunos se colocam no mundo, como se expressam e o que querem dizer, tendo como possibilidade a observação de aspectos negativos durante a dança, que podem significar problemas, como por exemplo, a conduta hipersexualizada.

7. Teatro - Divididos em grupos de até cinco alunos, cada grupo deverá escolher uma história ou um tema para representar, pertinente ao conteúdo a ser trabalhado pelo professor. A apresentação deve ter até quatro minutos e todos os alunos devem aparecer em cena.

Atividades abertas como estas favorecem a expressão corporal, que é capaz de exprimir aquilo que se vive ou se está imerso. Durante estas apresentações é possível

Educação, Psicologia e Interfaces, Volume 4, Número 3, p. 1-14, Julho/Setembro, 2020. ISSN: 2594-5343. DOI: $10.37444 /$ issn-2594-5343.v4i3.267 
Possíveis contribuições do professor de educação física na descoberta e prevenção de casos de violência sexual

compreender aquilo que está presente na vida dos alunos e como se posicionam em virtude disto. A expressão contida no corpo pode revelar problemas, caso existam.

8. Esportes - durante a ministração de aulas voltadas ao esporte, é possível a percepção de ações motoras não pertinentes. Como por exemplo, condutas hipersexualizadas, conhecimento inadequado para a idade, agressão e autoagressão, estresse, isolamento e depressão. Este tipo de ação é comumente encontrado no esporte, visto que os sintomas aparecem de modo impulsivo.

\section{CONSIDERAÇÕES FINAIS}

Para que o conhecimento deste assunto tão importante ocorra, é necessário que a escola se prontifique a apresentar e trabalhar de forma adequada o tema em questão, que esteja aberta a falar de assuntos pertinentes, conscientizando possíveis agressores e vítimas que muitas das vezes, por não estarem cientes das consequências de suas atitudes, perpretam atos que futuramente poderão se tornar traumas irreparáveis.

A educação sexual é uma das formas mais eficazes de promover a prevenção da violência sexual contra crianças e adolescentes. É por meio da educação sexual que se cria um ambiente seguro e de liberdade para que os alunos se comuniquem com familiares, educadores e outros profissionais da rede de proteção, caso estejam enfrentando esse tipo de violência (MEYER, p. 108, 2017).

A escola aparece como fonte primária de conhecimento nos casos em que a família é a agressora, casos estes que são maioria. Contando com a instrução para esclarecer situações e desmistificar tabus, torna-se possível diluir a perpetuação da violência sexual, quando pondo fim ao ciclo de silêncio.

A abordagem do tema pode cooperar, portanto, não só na prevenção da violência sexual, mas de doenças sexualmente transmissíveis, gravidez indesejada, assim como do conhecimento do próprio corpo. Além de que, manter o assunto oculto não faz com que ele não exista, mas sim que permaneça existindo de maneira oculta.

O professor de educação física, como representante da cultura corporal de movimento dentro da escola, tem o privilégio de trabalhar com a corporeidade do aluno, dentro de uma área de conhecimento estabelecida com linguagem. Por esse motivo, ações em suas aulas, como o trabalho de jogos, brincadeiras, esportes, danças, atividades de 
expressão corporal não podem ficar alheios a reflexão coletiva e critica, bem como a apreciação cuidadosa do professor sobre os seus alunos e os aspectos aqui citados, como o medo de se defender, dificuldade de intimidade, receio ao controle corporal, distorção do senso de realidade, entre outros.

Assim, o professor estabelece além de mecanismos de prevenção, a observação sistemática para a descoberta de problemas associados a abusos e agressão de seus alunos, cumprindo seu papel didático e humano.

\section{REFERÊNCIAS}

ABRAPIA. Associação brasileira multiprofissional de proteção à infância e adolescência. Abuso sexual contra crianças e adolescentes, mitos e realidades.

BNCC. Base Nacional Comum Curricular. Educação é a base. Disponível em: $<$ http://basenacionalcomum.mec.gov.br/wpcontent/uploads/2018/06/BNCC_EI_EF_110518_versaofinal_site.pdf $>$ acesso em 10.09.2018.

BORGES, J. L.; DELL'AGLIO, D. D. Relações entre abuso sexual na infância, transtorno de estresse pós-traumático (TEPT) e prejuízos cognitivos. Psicol. estud., Maringá, v. 13, n. 2, p. 371-379, 2008.

BRASIL. Lei no 8.069, de 13 de julho de 1990. Dispõe sobre o Estatuto da Criança e do Adolescente e dá outras providências. Diário Oficial [da] República Federativa do Brasil, Brasília, DF, 16 jul. 1990.

BRINO, R. F.; WILLIAMS, L. C. As concepções da professora acerca do abuso sexual infantil. Cadernos de Pesquisa. n.119, 2003.

CASTELO BRANCO, C. S. Sexualidade e violência: as instituições como lugar de sua perpetuação. Dissertação (mestrado) - Universidade Estadual de Campinas. Faculdade de Educação, Campinas, SP, 1999.

CASTRO-SANDOVAL, G. et al. Impacto de las politíticas de educación sexual em la salud sexual y reproductiva de adolescente em el sur de Chile, período 2010 - 2017. Revista chilena de obstetrícia y ginecologia. v.84, n.1, p.28-40, 2019.

CHILDHOOD. Pela Proteção da Infância. Disponível em: < http://www.childhood.org.br/como-agir> acesso em 14.10.2019

DIREITOS DA CRIANÇA. Portal direitos da criança e do adolescente. Tipologia do abuso sexual. Disponível em:

<http://www.direitosdacrianca.gov.br/midiateca/publicacoes/abuso-sexual > acesso em 16.10.2018. 
Possíveis contribuições do professor de educação física na descoberta e prevenção de casos de violência sexual

EHRENBERG, M. C. A linguagem da cultura corporal sob o olhar de professores da educação infantil. Pro-Posições. v. 25, n. 1 (73), p. 181-198, 2014.

FALEIROS, V. P e FALEIROS, E. S. Escola que protege: enfrentando a violência contra crianças e adolescentes. Brasília: Ministério da Educação, Secretaria de Educação Continuada, Alfabetização e Diversidade, $2^{\circ}$ edição, 2008

FREUD, S. Projeto para uma psicologia científica. Edição standard brasileira das obras psicológicas completas de Sigmund Freud, v. 1, p.1895, 1950.

GOMES-DA-SILVA, E., SANT’AGOSTINO, L. H. F., \& BETTI, M. Expressão corporal e linguagem na Educação Física: uma perspectiva semiótica. Revista Mackenzie da Educação Física e Esporte, São Paulo, p. 29-38, 2005.

HABIGZANG, L. F. et al. Abuso sexual infantil e dinâmica familiar: aspectos observados em processos jurídicos. Psicologia: Teoria e Pesquisa. v. 21, n. 3, p. 341 $348,2005$.

IPEA. Instituto de Pesquisa Econômica Aplicada. Estupro no Brasil: Vítimas, autores, fatores situacionais e evolução das notificações no sistema de saúde entre 2011 e 2014. Disponível em:

<http://www.ipea.gov.br/portal/images/stories/PDFs/TDs/td_2313.pdf > acesso em 15.10.2018.

LISBOA, C. et al. Estratégias de coping de crianças vítimas e não vítimas de violência doméstica. Psicol. Reflex. Crit, Porto Alegre, v. 15, n. 2, p. 345-362, 2002.

MEYER, C. A. "O que é privacidade?": uma ferramenta de prevenção da violência sexual para crianças. Dissertação (mestrado) - Universidade Estadual Paulista, Araraquara, SP, 2017.

SCARPATO, M. T. Dança educativa: um fato em escolas de São Paulo. Cad. CEDES, Campinas, v. 21, n. 53, p. 57-68, 2001.

SOUZA, R. S. D., \& DIESEL, V. Metodologia da pesquisa, 2008

STRAZZACAPPA, M. A educação e a fábrica de corpos: a dança na escola. $\boldsymbol{C a d}$. CEDES. vol.21, n.53, p.69-83, 2001.

VAYER, P. e TOLOUSE, P. Linguagem corporal: a estrutura e a socióloga da ação. Artes Médicas, 1985.

WILLIAMS, L. C. A. Abuso sexual infantil. Sobre Comportamento e Cognição: Expondo a Variabilidade. p. 155-164, 2002.

Credenciais da/os autora/es

Educação, Psicologia e Interfaces, Volume 4, Número 3, p. 1-14, Julho/Setembro, 2020.

ISSN: 2594-5343. DOI: 10.37444/issn-2594-5343.v4i3.267 
NASCIMENTO, Jessica Luiza de Oliveira. Universidade Estadual do Norte do Paraná/Brasil. E-mail: jessica.onasc@gmail.com

SIBILA, Miriam Cristina Cavenaghi. Universidade Estadual do Norte do Paraná/Brasil. E-mail: miriamccsibila@gmail.com

GUARIGLIA, Débora Alves. Universidade Estadual do Norte do Paraná/Brasil. E-mail: debora.guariglia@gmail.com

Endereço para correspondência: E-mail: jessica.onasc@ gmail.com

Como citar este artigo (Formato ABNT): NASCIMENTO, Jessica Luiza de Oliveira; SIBILA, Miriam Cristina Cavenaghi; GUARIGLIA, Débora Alves. Possíveis contribuições do professor de educação física na descoberta e prevenção de casos de violência sexual. Educação, Psicologia e Interfaces, v. 4, n.3, p. 1-14, 2020.

Recebido: 07/04/2020.

Aceito: 20/05/2020. 